\title{
"Hop on the bus, Gus."
}

\author{
Editorial \\ "Human babies are not born talking, \\ any more than they are born walking. " (Tim Ingold) ${ }^{1}$
}

In 1873 Edouard Manet finished his famous and beautiful "Railroad" painting. In it a woman in a blue travel coat, sitting on the stone base of a gate, stares us in the face, looking up from her book and gazing through us as if digesting what she just read, a little dog sleeping on her lap. Next to her a girl (her daughter?) stands with her back toward us, a big blue bow on her white Sunday dress, gripping the gate bars and looking through them at ... a cloud of steam. No train in sight. They are waiting, for what, for whom? Perhaps the girl's attention is not drawn by what she sees but by what she hears: a steam valve must be hissing loudly. ${ }^{2}$

Although Manet no doubt had another impression to convey when he conceived his painting, for me, as an historian of mobility, his piece represents the ambiguity of what the present journal is all about: are we to get a better grip on mobility through our sources, through reading, and contemplating them (our back towards the world of mobility, ourselves sitting still), or should we try to gaze through the clouds of steam surrounding the artifacts themselves (as a novice, in the white dress of innocence)? Should we delve into history or observe current movement? Should we hop on the bus of history (and don't discuss much, as Paul Simon's song continues) or ask ourselves the most fundamental and apparently naïve questions (like why are babies not born walking)? Whatever the answers to these questions, as they will emerge in the coming volumes of Transfers, it is quite clear that we, as an editorial team, are fascinated not only by the bare object of our studies, but also by the way we, and those before us, have tended to look at it. We want to know more about the train as well as the steam cloud behind which it is assumed to be hiding. We also want to know about the people who are trying to look at it, and those who are turning their backs to it. We want to understand.

And while we do this, we take a step back and acknowledge that the image has been painted, and thus represents only one impressionist way of dealing with mobile reality. Called Railroad (chemin-de-fer), not Train, the painting seems to convey an impression of a system rather than an artifact, and although it is about mobility nothing moves except the cloud. If they are waiting to catch their train, the scene also tells us that the immobility 
of the woman and child can be continued once on board, still-life moving through the landscape. Thus, Manet's painting is about expectation, the promise of mobility, and it points to the paradox that this (Western?) type of mobility can only be realized within a sedentary context.

Now, nearly one-and-a-half centuries later, at a moment when the communication giant Google is experimenting with robot cars, and women pop idols seem to abandon the car as an icon of modernity in their latest clips, ${ }^{3}$ the "system of mobility" has expanded all over the globe. It enables the movement of myriads of people, goods, and messages, but it produces one dead human being every thirty seconds, and threatens to change the earth's climate irreversibly, if it has not already done so. ${ }^{4}$ We have learnt to believe traffic engineers who declare that road safety is better than ever before, showing us their constantly decreasing death rate statistics that promise the paradise of "zero accidents." We have learnt to cloak our racism in an ecological concern about China and India's motorization, now that the former has become the world's largest car producer as well as the world's largest manager of a high-speed railway network. ${ }^{5}$

Not by coincidence is the car no longer icon number one among American youth: driving license ownership is decreasing among this group while ownership of iPhones and iPods is increasing. ${ }^{6}$ As a consequence, the new Nissan Cube has been launched not as a car but as a device "to bring people together-like every mobile device they have." ${ }^{7}$ While Manet's painting was conceived at about the start of a transition to motorized road vehicles, we seem to be heading to a comparable transition away from the car as the very epithet of modernity. Or are we?

Modernity and mobility, what an explosive pair! We lament the exclusion of poor people in the West from private and public transport but tend to protect ourselves from "The Shock of the Old," forgetting that the majority of humankind (four-fifths, according to a recent estimate ${ }^{8}$ ) still travels on foot, or on bicycle, or rickshaw, and may continue to do so for the coming generations. David Edgerton's eye-opening insight that we need "use-centered" rather than "innovation-centered" histories, ${ }^{9}$ easily applies to the realm of mobility: instead of over-emphasizing the importance of the car, as transport experts and sociologists specializing in "mobilities" have tended to do, it is salutary to realize that for most people travel speed has hardly increased during the past one-and-a-half centuries, while in the West myriads of incremental innovations (and some occasional innovative jumps) had to be implemented to keep the duration of the daily commute more or less constant. No doubt, walking is still humankind's central mobile activity, certainly if we include the domestic and the professional sphere in the equation, which has never seriously been done. In mobility matters, we may never have been modern, but can we conceive of a society, or a community, that modernizes or modernized 
without a car? Should we not look at The Rest rather than The West for inspiration? This is not only a question relevant to historians, but also to social scientists, policymakers and planners, and concerned citizens.

In order to answer the questions raised, the editorial team of Transfers: Interdisciplinary Journal of Mobility Studies intends to foster a new realm of academic inquiry, publishing the most cutting-edge work on mobility from a multitude of disciplinary and local perspectives. Intellectually rigorous, broad ranging, and conceptually innovative, Transfers will combine the empiricism of history with more recent methodological approaches that have reshaped the social sciences and the humanities. The journal's scholarly essays, book and exhibition reviews, artwork and photography, as well as special features (including its online extensions, see: http://journals.berghahnbooks.com/trans/) will offer new insights on mobility and its history as practice and institution, and the diverse ways it structures and is structured by contemporary life around the world. Transfers aims to bring into conversation a growing number of scholars (as well as artists, engineers, and policymakers) who, at present, remain mostly separated by disciplinary and institutional borders.

Convened around a broad conception of mobility, this global, multivocal conversation will include a rich variety of topics, perspectives, and claims, and will range from analyses of the past and present experiences of vehicle drivers, passengers, pedestrians, migrants, and refugees, to accounts of the arrival and transformation of mobility in different nations and locales, to investigations of the kinetic processes of global capital, technology, chemical and biological substances, images, narratives, sounds, and ideas. Without professing to a new, overall synthesis, we think that both the current mobility situation and the conditions in the history of transport and mobility (from whatever disciplinary flavor) are in such a flux that it is worthwhile indeed to have a place where such developments can be discussed, where borders can be tested and transgressed, and new vistas can be opened.

Such a journal, we think, should be independent, interdisciplinary and dedicated to top-quality contributions. We intend to reach this ambitious goal by following a thorough refereeing procedure designed to give special care to non-native speakers of English. We are after original work, but do not shy away from cutting-edge scholarship already published in a less accessible language (see Sloterdijk's piece in this issue). We will also experiment with other forms than the mainstream Anglo-Saxon essay as we recognize that by forcing every contributor into this standard mould we will lose the creativity of colleagues who are used, in their language, to conceive their texts differently. Our criterion is quite simple: the scholarly essays that we publish should help us rethink mobility. We are therefore 
less interested in the umpteenth tramway company's emergence and decline or the motorization of a country not yet part of the common stock. There are excellent journals out there that cater for this type of scholarship. Instead, we are looking for material with a twist: if this tramway company's analysis or this country's narrative shakes our conception of what it means (and meant) to be mobile we are eager to receive it and give it a try. And we hope our readers will too. As a matter of fact we would not be content creating an outlet whose readership more or less covers the potential number of its contributors, as is often the case in academic journals. In offering high-quality and cutting-edge scholarship, Transfers' readers should be able to count on thought-provoking stuff, stuff that invites them to look over the borders of their specialty, stuff that helps them (as it did us when we prepared it) to rethink the very concept of mobility, stuff that incites them (as it does us) to take a stand in matters of accessibility, equity, pollution, and other issues of mobility politics. For this, we aim at a large audience interested in being part of an avant-garde that desires to make a difference.

Thus, Transfers encourages scholarship that attends not only to people's construction of the technologies and regimes of mobility, but also to the ways in which those technologies and regimes construct and position us as subjects. For this, we need to rethink the very concept of mobility, as it has recently been understood by transport experts, mobility historians and sociologists of mobilities: rethink, indeed, the concept's Western exceptionalism ${ }^{10}$ and distinguish between "materialized mobility" and the opportunities to move, a distinction which makes Immanuel Kant a very mobile person indeed even if he never left Königsberg. "I "It should be possible," Nigel Thrift expects, citing C. Miller, "to arrive at 'a less utopian, less arrogant, and less messianistic theorisation of movement, a positive cosmopolitanism that remains meticulously aware of localities and differences, a more convincing ethic of flow.'"12 The mobilities we wish to explore include communication, because, to give only one example that springs to mind, German and American tanks at the start of the Second World War were already equipped with VHF radio. ${ }^{13}$ This issue contains another example (see Dorit Müller's paper): analyzing movies benefits our understanding of contemporary car driving, and vice versa. Other examples (continuing our associational meanderings through the vast reservoirs of potential topics of Transfers) also include Somalian pirates who accuse the West of emptying their coastal waters of fish, or the illegal tapping of Shell's pipelines in Nigeria, where locals produce their own petrol and kerosene in distilleries, working on open fires and sending large smoke flags into the sky. ${ }^{14}$ Such a broad approach cannot be dealt with within a single academic discipline. 
At present there is no journal devoted to interdisciplinary (let alone transdisciplinary) approaches to mobility and its history. The composition of our team already makes clear that our roots are only very partially in the field of transport history or the sociology of mobilities: Transfers invites transdisciplinary, transnational and transmodal scholarship prepared to decenter the vehicle while realizing that in order to transform and transfer, people, ideas and messages physically have to move. ${ }^{15}$

Transdisciplinarity is more than putting people from different disciplinary background in one editorial board. For a journal it is first and foremost about learning not to reject submissions because they do not follow one's familiar scholarly ritual, for readers it is about being open to the ways of thinking of other scholarly "tribes" and the preparedness to hybridize. While interdisciplinarity fosters the transfer of knowledge and practices over the borders of the disciplines, transdisciplinarity celebrates this hybridity in an effort to create a new holistic unity of knowledge. We call this new unity New Mobility Studies (but left the "New" out of the journal's subtitle in order not to sound like a detergent's publicity campaign) and are currently preparing a separate book series around this topic area, to be published by a major academic publisher.

Transnationalism is more than looking at supranational flows and institutions. It is about finding the global in the local and about realizing that what might be true for a globalized avant-garde is not necessarily true for the millions who, delinked from the global flows, move around in quite a different fashion-or are prevented from moving (such as during the hukou period in China, or in the case of the Western poor excluded from the "fast lane") or sent to err (as in the Soviet Union with its deliberately forged maps). Nomadism as a permanent form of existence is very different from the Western supposition that only movements that emerge out of sedentarism (such as car driving) deserve to be called mobility. The same applies to jogging, hiking, cruising and strolling. ${ }^{16}$ Transnationalism, then, is also about subversive mobility, and subaltern mobility, and the recognition that there are "multiple mobilities," just like there are "multiple modernities."

Subversive mobilities, going against the grain of hegemonic transport, can be found in the American jitneys during the First World War, when 60,000 illegal collective taxicabs were blossoming, including in southern black communities. It can be found in the same period and location when hobos were "ridin' the rods," breaking through the passivity and order regular passengers were forced into, and reminding us that America was a class society despite its self-declared classlessness celebrated in its railway wagons without compartments. ${ }^{17}$ It can be found in the Netherlands during the 1920s, when women were a tiny minority among the motorists but dominated bus tourism, or claimed the car's backseat. And it can 
be found in the thousands of Chinese peasants who used trains in the Interbellum years to get their produce to the market. Subaltern mobility, moving around with no voice of your own, can be studied among the rickshaw pullers of Beijing, when they started a violent riot in 1929 and opposed the introduction of the tramway; or in the nomadic Banjaras in Mumbai with their bullock carts specializing in the transportation of grain, sugar and salt in the nineteenth century, but called a "criminal tribe" by the colonial powers as they took up highway robbery or became railway station porters. ${ }^{18}$

Transmodality, finally, is not only about avoiding ghettoization along lines of transport systems (trains, cars, ships, planes) or including "slow traffic" into our spectrum, but also about making a "media turn," resisting partisanship when looking over the borders of traditional transport and mobility studies into the world of film, iPods, and other modes of communication. Who, for instance, would not love to read an analysis of the struggle between road and rail in the Interbellum written by someone who is not a partisan of one of the two transport modes, hardly able to hide a moral indignation about the historical actors of the other "camp"? And who would not love to write on real-life travelers who jump from pedestrianism to the bicycle, hop on the bus to the train station, and join a car tour in the countryside, all in one day? "No economic globalization without the gold standard, transportation technologies, and stock-market interconnectedness. No cultural globalization without TV, radio, and the Walkman," Wiebe Bijker exclaimed recently. ${ }^{19}$ But transmodality, in its radical forms which we would like to encourage, is also about discovering affinities between apparently diverse practices, such as walking and writing, or mobility, liberalism and language, ${ }^{20}$ (im)mobilities and art, or, to quote Peter Sloterdijk in this issue, between narcotics theory and mobility theory.

In launching our new journal, we also stress the limits of conventional historical practice at representing in their full complexity the worlds of mobility. Archival, documentary research is but one of the methodological resources at the contemporary scholar's disposal. Another is the "toolbox" of social, cultural, and aesthetic theory and practice that have been so instrumental in describing the worlds of modernity and postmodernity, including the growth and meaning of mobility. It is the explicit aim of Transfers to bridge fissures between the different scholarly realms of history writing and theoretical reflexivity, to reach out to all those scholarly nomads out there who hop from one subfield to another to satisfy their curiosity and academic rigor. We intend to do that not by throwing both in one pot, but by inviting the one to benefit from the other, requesting social scientists to include the materialism and experiences of movement, and 
historians to venture a bit more into reflexivity. The envisaged editorial team and board, as well as our network of referees, are composed of historians, social scientists, transport experts, literary scholars, artists, cultural critics, and policymakers, all of whom are committed to shaping a scholarly practice of New Mobility Studies that combines the insightful tools of theory and the empirical richness of the best historical work. Encouraging work that is provocative and challenging for its incorporation of theoretically speculative, multivocal, narratively experimental, and visually or textually interpretive contributions, this journal seeks to throw the net of editorial policy ever more widely, into all four types of mobility distinguished by Vincent Kaufmann. ${ }^{21}$ But we also realize that there will come a moment not far from now, that we will start a partial move back, in order to prevent the concept of "mobility" to become so all-encompassing that it loses its analytical potential. Mobility, in other words, should be a descriptive as well as an analytical tool. The aim of this journal is not to replace general history, but to offer a new way of looking on a crucial part of society, both modern and pre-modern. The "shock of the old" will help us here, as it recognizes the existence of an often-overlooked mobility culture that is not global, or avant-garde, or fluid, but locally isolated, delinked, subversive, and subaltern.

Transfers, then, is a methodological concept-and a political one. It refers to change, to transformations in mobility studies, because it pushes concepts from one discipline into another, from Mobility Studies to Travel Writing, for example, as the latter often forgets to include the vehicle as if this does not influence the traveler's experiences. Or vice versa, to inform mobility scholars that hedonism was as much a motive for technical innovation as utilitarian considerations. Mobility indeed has always been political and racially loaded, but whoever needs to have a reminder of this should think back to hurricane Katrina in the U.S., where evacuation plans had been built upon the car and the 200,000 carless were stuck in the rising water. ${ }^{22}$ Or they should realize that cycle rickshaw drivers in Delhi and other Indian metropolises, most of whom migrated from poorer agricultural states, depend on their vehicles to stay alive: streamlining the city's flows by abandoning "slow vehicles" from the streets, as proposed and implemented by traffic engineers and local governments, is a profoundly political act. Local activism in this case is informed by cuttingedge scholarship (and vice versa), by concerned historians of mobility, involved urban planners and recalcitrant traffic engineers. ${ }^{23}$

If it is true that it is our imagination that enables us to transfer or translate our experiences into knowledge about ourselves, then Manet's painting is a good example of what we are after. At the same time the term itself is vague enough to suggest movement without indicating for what, whereto, and how. Thus, Transfers opens itself to a shift in the senses 
experienced by Marcel Proust, a fervent de l'automobilisme, when he was driven around Normandy, seeing the steeples of some villages change position while his chauffeur, a "nun of speed," was playing the gearbox like an organ..$^{24}$ But Transfers is also about "forced removal," a recently coined new term for ethnic cleansing and genocide. ${ }^{25}$ And it is about pyramids that have been identified as seemingly immobile but present all over the world: "Stones, like sacred relics, travel and induce us to do likewise; they move us emotionally, spiritually, and in many other ways." ${ }^{26}$ This is not a mere play of words taken from the growing grab-bag of mobility studies. We believe we are onto something worth investigating further. In this, we are post-postmodernists: we are not afraid to take a position. We invite scholars who agree with us to convince our referees that your submissions on stones, and tectonic plates, and animals, and the world circulation of carbon or water, should be part of New Mobility Studies.

This journal, then, is aimed at following the cultural turns (going on in so many disciplines) through to its radical consequences. It is not aimed at creating a field in the sense of a new organization, but it does aim to break out of the ghetto called transport history (now also engaged in its cultural turn) by decentering several aspects that have been used to define the field so far, or function as constraints to our creativity.

In the first place we want to decenter the vehicle, and even transport itself, by including communication and infrastructure studies within our scholarly horizon. About a century ago, the study of "transport" was split off from communication (mail, telegraph, telephone). We wish to investigate in these pages why this was so and why it could be interesting to re-unite these subfields and see, for instance, the similarities between driving in a car and walking the city with iPod headphones in your ears. We want to understand how in the "splintered cities" of the new century, the "scapes" of "electropolis," "autocity" and "cybercity" are interconnected, co-evolving in ways that neither mobility histories nor urban histories have so far been able to reconstruct. ${ }^{27}$

Secondly, we wish to decenter the nation-state-even the West-by including transnational studies and what one could call subaltern mobility studies into our orbit, breaking the easy connection between modernity and the car. We want to see what it means for modernity if we acknowledge that mobility in the West often had collective characteristics (bicycling and motoring started in clubs, remember?) and that modernization in the East followed quite different trajectories from those in the West, or from "the South of the West" for that matter. ${ }^{28}$ The border between "provincialism" and "globalism" is fuzzy, but we think that no "national" analysis should be printed in this journal without at least a hint to the narrative's transnational setting. 
And, thirdly, we seek to decenter history by encouraging contributions from the fields of Science and Technology Studies (STS), as well as planning and policymaking into our journal, although we firmly believe that no analysis should be printed in our columns without at least some consideration of a long-term perspective.

We have come a long way: it took us three years to prepare our journal, refining our concepts of mobility and its history, building a solid financial base for our venture, and finding a publisher who was prepared, in the middle of the credit crisis, to engage into our new venture. Therefore, we would first and foremost like to thank all those (potential) contributors and (would-be) board members, who literally stayed on board during the last long period of uncertainty, for their trust in our vision and their eagerness to be a part of it. We want to call upon the readers to subscribe, because without one particular institutional affiliation (and dependency) we really need your individual trust and support.

The format of Transfers has been conceived to provide a kaleidoscopic view in multiple directions-mobility and film (Dorit Müller's section), art (Charissa Terranova's middle section), and museum exhibitions (Kurt Möser) - while an extensive book review section (managed by Rudi Volti) also generated two review essays to provoke critical conversation. In this first issue, as an antidote against the preponderance of the automobile, we invited a geographer (Jennifer Bonham) and an historian (Manuel Stoffers) to formulate their contrasting views on the recent bicycle boom, both on the street and, especially, in scholarly and activist publications. We created a separate section for this type of "essayistic" scholarship (called Ideas in Motion), where we also intend to place short pieces that directly confront current-day concerns of mobility and its scholars. In this first issue, we also decided to write the museum and film reviews ourselves, assuming that you, our readers, will take over from us from now on.

In the following issues we will publish several contributions to a series of three workshops organized from November 2008 through April 2009 by the Dutch Ministry of Traffic and Waterstaat. Here, for the first time to our knowledge, an important player within a national government recognized the importance of the practice of history making and writing for the internal (within the Ministry) and public debates on current problems of accessibility, exclusion from means of transport, and the modal split in congested urban areas. Perhaps, as indicated by one of the conclusions of the workshops, we need a kind of Applied History to help policymakers and planners to rethink mobility. We also need an overview of the state of the art, a wrap-up of where some of us are standing in the history of transport and mobility, to enable us to define more precisely what we wish to leave behind, so that we can join with others who are not familiar with this 
field's tradition, to co-construct New Mobility Studies. We are grateful to the Ministry, and to its historian Bert Toussaint in particular, for providing us with this opportunity and helping us in a crucial way to support not only these workshops but also the publication of their key results. Hence, this issue shows the hybrid character we are after: a balanced mix of state-of-the-art and gaze into the realm beyond. As to the former, Greet De Block (a participant to one of the Dutch Ministry's workshops) and Bruno De Meulder propose an alternative reading of Belgian urban planning, arguing against the easy conjunction of modernity and the car and its highways. The other contributions to this first issue are more programmatic or provocative, such as Heike Weber's plea to integrate media history and mobility history, and Charissa Terranova's claim that we need art, and its thorough analysis, to get a grip on what it means to be mobile in the West today. Dorit Müller's analysis of silent movies in the pioneering days of automobilism can be read as an application of Weber's plea and at the same time as a support of Terranova's claim as she emphasizes the profound aggressiveness of car driving and the affinities of violence between film and car as media. But we open our new journal with German philosopher Peter Sloterdijk's sweeping analysis of ur-mobility, programmatic and provocative at the same time. We thank professor Sloterdijk for his permission to have his text translated, and present this foundational piece as an announcement of how, in the following issues, we would like to open our minds and our practices to rethink mobility. If you, as a reader, agree that this is the way to deal with these issues, please feel invited to submit your contribution to Transfers.

\section{Gijs Mom}

Editor together with:

Georgine Clarsen

Nanny Kim

Cotten Seiler

Associate editors
Kurt Möser

Dorit Müller

Charissa Terranova

Rudi Volti

Review editors 


\section{Notes}

1. Tim Ingold, The Perception of the Environment: Essays on Livelihood, Dwelling and Skill (London/New York: Routledge, 2000), 377; "Hop on the Bus": Paul Simon, "50 Ways to Leave Your Lover," in Still Crazy After All These Years (1975), http:// lyrics.wikia.com/Paul_Simon:50_Ways_To_Leave_Your_Lover (consulted 17 January 2011).

2. Manet's "Railroad" was the central piece of a recent exhibition in Museum Folkwang, Essen (Germany), but is owned by the National Gallery of Art in Washington. Bilder einer Metropole: Die Impressionisten in Paris (Göttingen: Edition Folkwang/Seidl, 2010), 97 and cover.

3. Tobias Rapp, “Die Frauen übernehmen," Der Spiegel (2010) no. 28: 112-115.

4. Dean Slavnich, "Safety Drive," Traffic Technology International (January 2009): 20-27, here: 21.

5. "Trends Review: China; Growth and Technology Trends," Insight (September 2010): 1-2 (highest production figures are for 2009); "Supertrein doet China krimpen," NRC Handelsblad (13-14 February 2010): 16.

6. "Auto niet meer nummer 1 bij jeugd VS," Automobile Management (15 January 2010): 1 .

7. Stuart Elliott, "With the Car Industry in Trouble, Nissan Rolls Out the Mobile Device," New York Times (6 April 2009), http://www.nytimes.com/3009/04/06/ business/media/06adco.html (accessed 4 January 2010).

8. Nigel Thrift, Spatial Formations (London/Thousand Oaks/New Delhi: Sage, 1996), 293.

9. David Edgerton, The Shock of the Old: Technology and Global History since 1990 (Oxford: Oxford University Press, 2008 [2006]).

10. Michael Geyer and Charles Bright, "World History in a Global Age," The American Historical Review 100, no. 4 (October 1995): 1034-1060, here: 1041.

11. Jörg Beckmann, Risky Mobility; The filtering of automobility's unintended consequences (Copenhagen: Copenhagen University, Sociological Institute: 2001), 31.

12. Thrift, Spatial Formations, 293; Thrift quotes C. Miller, "The Postidentitarian Predicament on the Footnotes of A Thousand Plateaus," Diacritics 23 (1993): 6-35, here: 33.

13. Friedrich Kittler, "Unconditional Surrender," in Materialities of Communication, ed. Hans Ulrich Gumbrecht and K. Ludwig Pfeiffer (Stanford, CA: Stanford University Press, 1994), 319-334, here: 331.

14. Michael Persson, "Dweilen met de oliekraan open," De Volkskrant (26 November 2010), "Economie," 2-3; Auke Hulst, “Op zee-jihad naar het Westen; Verschillen en overeenkomsten tussen $17^{\mathrm{de}}$ - en $21^{\text {ste }}$-eeuwse piraterij," NRC Handelsblad (26 November 2010), "Boeken", 14: review of Adrian Tinniswood, Pirates of Barbary (Jonathan Cape, 2010).

15. Stephen Greenblatt, "A Mobility Studies Manifesto," in Cultural Mobility; A Manifesto, Stephen Greenblatt, with Ines G. Županov, Reinhard Meyer-Kalkus, Heike Paul, Pál Nyíri and Friederike Pannewick (Cambridge: Cambridge University Press, 2010), 250-253, here: 250.

16. Jennifer Bonham, “The Conduct of Travel; Beginning a Genealogy of the Travelling Subject” (unpubl. diss., University of Adelaide, June 2002), 9. 
17. John Lennon, “Ridin' the Rails: The Place of the Passenger and the Space of the Hobo," Americana: The Journal of American Popular Culture (1900-Present) 3, no. 2 (Fall 2004): 1-11.

18. Ian Kerr, Engines of Change: The Railroads That Made India (London: Praeger, 2007). I thank Saurabh Arora (Eindhoven University of Technology) for bringing this source to my attention. On Chinese farmers see: Jonathan D. Spence, The Search for Modern China (London: Hutchinson, 1990).

19. Wiebe Bijker, "Globalization and Vulnerability Challenges and Opportunities for SHOT around Its Fiftieth Anniversary," Technology and Culture 50, no. 3 (July 2009), 600-612, here: 603.

20. Bonham, "The Conduct of Travel," 31-32.

21. Vincent Kaufmann, "Between Social and Spatial Mobilities: The Issue of Social Fluidity," in Tracing Mobilities: Towards a Cosmopolitan Perspective, ed. Weert Canzler, Vincent Kaufmann and Sven Kesselring (Aldershot: Ashgate, 2008), 3755, here: 40-42. The four types are sedentary, cosmopolitan, re-embedded and incursive.

22. Ramona Lenz, Mobilitäten in Europa; Migration und Tourismus auf Kreta und Zypern im Kontext des europäischen Grenzregimes (Wiesbaden: VS Verlag für Sozialwissenschaften/Springer Fachmedien Wiesbaden, 2010) 63; on Katrina see: Tim Cresswell, On the Move: Mobility in the Modern Western World (New York/ London: Routledge, 2006), 261.

23. See the DVD released by Lokayan, out of which the Institute for Democracy and Sustainability evolved (Rajendra_Ravi@idsindia.net): Siksha, "Pedal Soldier of India" (Delhi, 2004).

24. Gijs Mom, Atlantic Automobilism (forthcoming).

25. Richard Bessel and Claudia B. Haag (ed.), Removing Peoples: Forced Removal in the Modern World (London: Oxford University Press, 2009).

26. The quote is from "world movie scholar" Teshome H. Gabriel (who died last year), in The Future of Knowledge and Culture: A Dictionary for the Twenty-first Century, ed. Ashis Nandy and Vinay Lal (Viking Penguin, 2006), http://vinaylal. wordpress.com/2010/06/16/friend-master-storyteller-scholar-and-humanistpar-excellence-reminiscences-of-teshome-h-gabriel/ (accessed 24 January 2011). I thank Cheryl Lousley (Rachel Carson Center, Munich; since recently: Lakehead University, Canada) for drawing this source to my attention.

27. Stephan Graham and Simon Marvin, Splintering Urbanism: Networked Infrastructures, Technological Mobilities and the Urban Condition (London/New York: Routledge, 2001).

28. Georgine Clarsen, “Automobility 'South of the West': Toward a Global Conversation," in Mobility in History: Themes in Transport ( $T^{2} M$ Yearbook 2011), ed. Gijs Mom, Peter Norton, Georgine Clarsen and Gordon Pirie (Neuchâtel: Alphil, 2010), 25-41. 
Gijs Mom is Associate Professor History of Technology and Mobility at Eindhoven University of Technology. The author of The Electric Vehicle; Technology and Expectations in the Automobile Age (Johns Hopkins UP, 2004), he is currently finishing a synthetic monograph on Atlantic Automobilism.

Georgine Clarsen is a Senior Lecturer in the History and Politics Program at the University of Wollongong. Her current research is on landscape and automobility in Australia.

Nanny Kim is a China historian at Heidelberg University. She is currently finishing a monograph on transport in the Chinese southwest, ca. $1700-1850$.

Cotten Seiler is Associate Professor and Chair of the American Studies Department at Dickinson College. The author of Republic of Drivers: A Cultural History of Automobility in America (Chicago, 2008), he is currently examining racial thinking in the postwar era.

Kurt Möser teaches history at the Karlsruhe Institute of Technology and is curator at the Technoseum in Mannheim. His latest book is on Fahren und Fliegen in Frieden und Krieg (Driving and Flying in Peace and War) (Heidelberg 2010).

Dorit Müller is a Lecturer at the German Department at Darmstadt University of Technology. Her work includes studies on early automobilism in film and literature. She is currently investigating the construction of Polar spaces in the media since the 19th century.

Charissa N. Terranova is Assistant Professor of Aesthetic Studies at The University of Texas at Dallas. Dr. Terranova is currently negotiating a publishing contract for her book Automotive Prosthetic: The Car, Technological Mediation, and the Conceptual Turn in Art, 1951-Present, which focuses on conceptual art, the aesthetic experience of seeing the world in motion through the car window, and the global political economy of the car in the post-WW II period.

Rudi Volti is Professor Emeritus of Sociology at Pitzer College. His publications include Society and Technological Change (ed. 6, 2008) and Cars and Culture: The Biography of a Technology (2006). 